\title{
STUDI KELAYAKAN EKONOMI PEMBANGUNAN UNDERPASS \\ PADA SIMPANG JL. GATOT SUBROTO-JL. AHMAD YANI DI KOTA DENPASAR
}

Lina Sarasdevi Santosa ${ }^{1}$, P. Alit Suthanaya ${ }^{2}$ I B. Rai Adnyana ${ }^{2}$

\begin{abstract}
Abstrak : Berdasarkan data Badan Pusat Statistik (BPS) Provinsi Bali tahun 2013, tingkat kepadatan penduduk di wilayah Metropolitan SARBAGITA (Denpasar-Badung-Gianyar-Tabanan) sebesar $1.057 \mathrm{jiwa} / \mathrm{km}^{2}$ dengan luas wilayah sebesar 1.753,63 $\mathrm{km}^{2}$ dan jumlah penduduk sebanyak 1.853.017 jiwa. Ketersediaan sarana dan prasarana transportasi yang memadai sangat dibutuhkan, namun nyatanya kinerja ruas jalan di pusat kota kian menurun. Hal tersebut ditandai dengan adanya peningkatan masalah tundaan perjalanan. Permasalahan tundaan lalu lintas di Kota Denpasar yang umum terjadi pada ruas Jl.Gatot Subroto. Untuk meminimalisir permasalahan yang ada maka Pemerintah Kota Denpasar merencanakan pembangunan underpass pada simpang Jl. Gatot Subroto-Jl. Ahmad Yani di Kota Denpasar.

Tujuan dari penelitian ini adalah untuk menganalisis manfaat langsung pembangunan underpass bagi pemakai jalan, untuk menganalisis besarnya biaya yang diperlukan untuk mewujudkan serta mengoperasikan underpass dan untuk menganalisis kelayakan ekonomi investasi pembangunan underpass.

Berdasarkan data primer dan data sekunder yang diperoleh dari instansi pemerintah, metode analisis dalam studi ini menggunakan teknik Net Present Value (NPV), Benefit Cost Ratio (BCR) dan Internal Rate of Return (IRR).

Hasil analisis ekonomi yang dilakukan menurut tiga kriteria dengan tiga tingkat suku bunga (12\%, 15\% dan 18\%) menyatakan bahwa Pembangunan underpass layak secara ekonomi. Sebagai contoh pada skenario II dimana tingkat suku bunga $15 \%$ mendapat hasil analisis berupa nilai NPV, BCR dan IRR berturut-turut adalah Rp. 233.462.340.102,00; 1,948 dan 30,81\%.

Saran yang dapat disampaikan dari penelitian ini adalah perlu dipertimbangkannya pengaruh perubahan tata guna lahan di daerah-daerah yang dekat dengan wilayah sekitar underpass serta diperlukan adanya kajian lebih lanjut yang memperhitungkan kebutuhan penambahan lajur lalu lintas.

Kata Kunci : Jalan Underpass, Kelayakan Ekonomi
\end{abstract}

\section{ECONOMIC FEASIBILITY STUDY OF UNDERPASS DEVELOPMENT ON GATOT SUBROTO-AHMAD YANI CROSS-ROADS IN DENPASAR}

Abstract : Based on data from the Central Statistics Agency (BPS) of Bali in 2013, the population density in the Metropolitan area SARBAGITA (Denpasar-Badung-Gianyar-Tabanan) was 1.057 inhabitants $/ \mathrm{km}^{2}$ with an area of $1.753,63 \mathrm{~km}^{2}$ and population was 1.853 .017 inhabitants. Availability of facilities and adequate transportation infrastructure is needed, but in fact the performance of roads in the city center has declined. It is characterized by an increase in travel delay problem. Traffic delay problems in the City of Denpasar commonly occur on the stretch of Gatot Subroto street. To minimize the existing problems, Denpasar City Government plans to develop an underpass at the intersection of Gatot Subroto street and Ahmad Yani street.

The aim of this study was to analyze the direct benefits of underpass for road users, to analyze the costs necessary to realize and operate the underpass, and to analyze the economic feasibility of the underpass development investment.

Based on primary data and secondary data were obtained from government agencies, the method of analysis in this study used the technique of Net Present Value (NPV), Benefit Cost Ratio (BCR) and Internal Rate of Return (IRR).

Economic analysis conducted in this study used three criteria (NPV, BCR and IRR) with three interest rates $(12 \%, 15 \%$ and $18 \%$ per year) stating that the construction of an underpass was economically feasible. For example in the second scenario where the interest rate $15 \%$ gain on the analysis of value NPV, BCR and IRR respectively is Rp. 233.462.340.102,00; 1,948 and 30,81\%.

Suggestions can be submitted from this research is the need to contemplate the effect of changes in land use in areas close to the area around the underpass and needed further study that takes into account the needs of additional traffic lanes.

Keywords : Road Underpass, Economic Feasibility

\footnotetext{
${ }^{1}$ Mahasiswa Program Magister Teknik Sipil, Program Pascasarjana, Universitas Udayana, Denpasar

${ }^{2}$ Staf Pengajar Program Magister Teknik Sipil, Program Pascasarjana, Universitas Udayana, Denpasar
} 


\section{PENDAHULUAN}

\section{Latar Belakang}

Ruas Jl. Gatot Subroto tergolong jalan arteri primer tipe 4 lajur 2 arah tak terbagi/ UnDevided (4/2 UD). Berdasarkan fungsinya sebagai jalan arteri mengakibatkan Jl. Gatot Subroto banyak dilintasi oleh masyarakat dari dalam ataupun luar wilayah kota Denpasar.

Berdasarkan hasil studi yang dilakukan Sandiguna (2013), kinerja simpang eksisting Jl. Gatot Subroto - Jl. Cokroaminoto diperoleh nilai tundaan untuk semua jam puncak > 40 detik/smp sehingga nilai tingkat pelayanan simpang untuk semua jam puncak adalah sangat macet $(\mathrm{F})$.

Bangkitan lalu lintas di wilayah tersebut dikarenakan makin pesatnya pertumbuhan pusat perkantoran di kawasan Lumintang ditambah lagi dengan dibangunnya Pusat Pemerintahan Kota Denpasar. Menurut Mahendra (2013), hasil analisis simpang tak bersinyal Jl. Gatot Subroto - Jl. Mulawarman - Jl. Mataram pada jam puncak tertinggi dengan tingkat pelayanan $F$ dan derajat kejenuhan (DS) sebesar 1,97 serta hasil analisis simpang tak bersinyal jalan Ahmad Yani - jalan Mulawarman pada jam puncak tertinggi dengan tingkat pelayanan $\mathrm{F}$ serta nilai DS sebesar 1,48.

Pengelolaan lalu lintas dengan sistem satu arah pada pola jaringan jalan HOS. Cokroaminoto, jalan Gatot Subroto, jalan Mulawarman dan jalan Ahmad Yani untuk mengurangi masalah kemacetan dan tundaan telah dikaji oleh Ariyasa (2013). Dari hasil studi tersebut diperoleh perbandingan kinerja simpang dan ruas untuk kedua kondisi pada jam puncak pagi meningkat sebesar 132,45\%, jam puncak siang meningkat sebesar 232,57\% dan jam puncak sore meningkat sebesar $246,92 \%$.

Untuk meminimalisir permasalahan yang ada maka Pemerintah Kota Denpasar merasa perlu untuk diadakannya pembangunan underpass pada simpang Jl. Gatot Subroto-Jl. Ahmad Yani. Mengingat besarnya dana yang dibutuhkan dan kas keuangan pemerintah yang terbatas sehingga perlu diadakan suatu kajian kelayakan terlebih dahulu. Pada penelitian ini mengkaji kelayakan dari sisi ekonomi pembangunan underpass pada simpang Jl. Gatot Subroto-Jl. Ahmad Yani berdasarkan trase terpilih.

\section{Rumusan Masalah}

1. Berapakah besarnya biaya yang dibutuhkan untuk mewujudkan dan mengoperasikan underpass?
2. Bagaimanakah manfaat langsung pembangunan underpass bagi pemakai jalan berdasarkan analisis terhadap variabel-variabel penghematan $\mathrm{BOK}$ dan nilai waktu?

3. Bagaimanakah kelayakan ekonomi pembangunan underpass berdasarkan manfaat yang diperoleh dan biaya yang diperlukan untuk mewujudkannya?

Tujuan Penelitian

1. Untuk menganalisis besarnya biaya yang dibutuhkan untuk mewujudkan dan mengoperasikan underpass.

2. Untuk menganalisis manfaat langsung pembangunan underpass bagi pemakai jalan berdasarkan analisis terhadap variabel-variabel penghematan $\mathrm{BOK}$ dan nilai waktu.

3. Untuk menganalisis kelayakan ekonomi pembangunan underpass berdasarkan manfaat yang diperoleh dan biaya yang diperlukan untuk mewujudkannya.

\section{KAJIAN PUSTAKA}

\section{Studi Kelayakan Proyek}

Studi kelayakan adalah suatu kegiatan penelitian atau studi yang dilakukan secara komprehensif dari berbagai aspek dalam usaha mengkaji tingkat kelayakan dari suatu proyek (LPM-ITB, 1997).

\section{Tujuan dan Manfaat Studi Kelayakan}

Santosa (2011) menyebutkan bahwa suatu studi kelayakan memiliki tujuan, antara lain :

1. Menghindari terjadinya keterlanjuran penanaman modal yang tidak menguntungkan.

2. Memaksimalkan keuntungan.

3. Mengevaluasi aspek-aspek yang mempengaruhi suatu studi.

4. Mengidentifikasi faktor-faktor yang menjadi kunci keberhasilan.

5. Mengidentifikasi sarana dan prasarana yang dibutuhkan.

Suatu proyek dinilai bermanfaat dari segi finansial jika nilai ekonomis dari proyek tersebut dapat menguntungkan bila dibandingkan dengan resiko yang ditimbulkan. Manfaat ekonomi yang dimaksudkan adalah manfaat proyek tersebut di tempat pelaksanaannya dan berpengaruh luas terhadap wilayah sekitarnya. Manfaat sosial ialah manfaat yang dihasilkan darimana lokasi proyek tersebut dilaksanakan. Manfaat 
lingkungan mencakup polusi udara, air, tanah maupun suara yang ditinjau dari tahap pra pelaksanaan sampai pasca proyek. Manfaatmanfaat tersebut berlaku untuk setiap studi kelayakan, baik itu yang bersifat komersil maupun proyek investasi.

\section{Persimpangan Tak Sebidang}

Persimpangan merupakan pertemuan antara dua jalan atau lebih, baik sebidang maupun tidak sebidang atau titik jaringan jalan dimana jalan-jalan bertemu dan lintasan jalan saling berpotongan (Morlok, 1991).

Pembangunan simpang tak sebidang atau susun dilakukan untuk memperbesar kapasitas jalan, menambah keamanan dan kenyamanan bagi pemakai jalan. Bentuk simpang tak sebidang dapat berupa jembatan layang (Flyover), terowongan (Underpass) dan persilangan yang dapat berpindah dari ruas yang satu ke ruas yang lain (Interchange).

\section{Biaya Operasional Kendaraan}

Menurut pedoman perhitungan BOK yang dikeluarkan oleh Departemen PU, komponen BOK terdiri atas :

\section{$\checkmark \quad$ Biaya tidak tetap}

a. Pemakaian bahan bakar

b. Pemakaian minyak pelumas

c. Pemakaian suku cadang

d. Upah tenaga pemelihara

e. Pemakaian ban

$\checkmark \quad$ Biaya tetap

a. Biaya penyusutan (Depresiasi)

b. Bunga modal

c. Asuransi

\section{Nilai Waktu}

Besarnya nilai waktu bagi pengguna jalan merupakan gambaran dari layanan konsumen yang diberikan oleh jalan kepada pengguna jalan tersebut (LPM-ITB, 1997). Dalam studi kelayakan proyek jalan, nilai waktu digunakan untuk menghitung besarnya manfaat yang didapat oleh pengguna jalan akibat adanya penghematan waktu jika melewati jalan baru.

Besarnya penghematan BOK dan nilai waktu dihitung menurut persamaan di bawah: $\mathrm{PB}=\left(\mathrm{BOK}_{\mathrm{ek}} \times \mathrm{D}_{\mathrm{ek}}-\mathrm{BOK}_{\mathrm{alt}} \times \mathrm{D}_{\mathrm{alt}}\right)+\left\{\left(\mathrm{D}_{\mathrm{ek}} / \mathrm{V}_{\mathrm{ek}}\right.\right.$

$$
\left.\left.-\mathrm{D}_{\text {alt }} / \mathrm{V}_{\text {alt }}\right) \times \mathrm{Tv}\right\}
$$

Dimana :

$\mathrm{PB}=$ Penghematan biaya pengguna $(\mathrm{Rp})$

$\mathrm{BOK}_{\mathrm{ek}}=$ Biaya operasi kendaraan di jalan eksisting $(\mathrm{Rp} / \mathrm{km})$

$\mathrm{BOK}_{\mathrm{alt}}=$ Biaya operasi kendaraan di jalan alternatif (Rp/km)

$\mathrm{D}_{\mathrm{ek}} \quad=$ Panjang jalan eksisting $(\mathrm{km})$
$\mathrm{D}_{\text {alt }} \quad=$ Panjang jalan alternatif $(\mathrm{km})$

$\mathrm{V}_{\mathrm{ek}}=$ Kecepatan di jl. eksisting $(\mathrm{km} / \mathrm{jam})$

$\mathrm{V}_{\text {alt }} \quad=$ Kecepatan di jl. alternatif $(\mathrm{km} / \mathrm{jam})$

$\mathrm{Tv}=$ Nilai waktu kendaraan $(\mathrm{Rp} / \mathrm{jam})$

\section{Biaya Proyek}

Biaya suatu proyek dapat dibagi menjadi dua kelompok yakni biaya modal dan biaya operasional (LPM-ITB, 1997) sebagai berikut :

1. Biaya modal adalah biaya-biaya yang dikeluarkan untuk menyiapkan dana proyek, melakukan studi, penyiapan dokumen pembangunan atau pelaksanaan konstruksi, pengawasan pembangunan dan manajemen proyek.

2. Biaya operasional adalah biaya yang dikeluarkan untuk kegiatan operasional meliputi: proses menjalankan proyek, pemeliharaan, perbaikan serta pengelolaan selama masa pelayanan.

\section{Pendekatan Kelayakan Investasi}

Kriteria dasar untuk mengukur manfaat suatu investasi pada bidang transportasi adalah dengan melakukan perhitungan "dengan” dan "tanpa” ("with” and "without”) pembangunan jalan baru sehingga diketahui keuntungan yang timbul karena adanya pembangunan jalan baru tersebut. Kriteria evaluasi dalam analisa ekonomi umumnya adalah Net Present Value (NPV), Benefit Cost Ratio (BCR), Internal Rate of Return (IRR) dan Analisis Sensitivitas.

\section{Net Present Value}

Metode NPV adalah metode yang membandingkan semua komponen biaya dan manfaat suatu proyek dengan acuan yang sama agar dapat diperbandingkan satu dengan lainnya (LPM-ITB,1997). Secara matematis persamaannya adalah sebagai berikut :

$\mathrm{NPV}=\mathrm{PV} \mathrm{B}-\mathrm{PV} \mathrm{C}$

$\mathrm{NPV}=\sum_{\mathrm{t}=0}^{\mathrm{n}} \frac{\mathrm{B}_{\mathrm{t}}-C_{t}}{(1+i)^{t}}$

Dimana :

$\mathrm{PV} \mathrm{B}=$ Present Value Benefit

$\mathrm{PV} \mathrm{C}=$ Present Value Cost

$\mathrm{Bt}=$ Besaran total dari komponen manfaat proyek pada tahun $\mathrm{t}$

$\mathrm{Ct}=$ Besaran total dari komponen biaya pada tahun $\mathrm{t}$

$i \quad=$ Tingkat suku bunga (\% per tahun)

$\mathrm{t} \quad=$ Jumlah tahun

\section{Benefit Cost Ratio}

Metode ini membandingkan semua pemasukan (dihitung pada kondisi saat ini) 
dengan semua pengeluaran (dihitung pada kondisi saat ini). Secara matematis dapat dirumuskan sebagai berikut :

$\mathrm{BCR}=\mathrm{PV} \mathrm{B} / \mathrm{PV} \mathrm{C}$

$$
\mathrm{BCR}=\frac{\sum_{\mathrm{t}=0}^{n} \frac{\mathrm{Bt}}{(1+\mathrm{i})^{\mathrm{t}}}}{\sum_{\mathrm{t}=0}^{n} \frac{\mathrm{C} \mathrm{t}}{(1+\mathrm{i})^{\mathrm{t}}}} \ldots \ldots \ldots \ldots \ldots
$$

Dimana :

$\mathrm{Bt}=$ Besaran total dari komponen manfaat proyek pada tahun $t$

$\mathrm{Ct}=$ Besaran total dari komponen biaya pada tahun $\mathrm{t}$

$i=$ Tingkat suku bunga (\% per tahun)

$\mathrm{t} \quad=$ Jumlah tahun

\section{Internal Rate of Return}

IRR sering juga disebut sebagai laju pengembalian modal. Dalam hal ini laju pengembalian modal dapat dianggap sebagai tingkat keuntungan atas investasi bersih dalam suatu proyek. Jika besarnya laju pengembalian modal ini melebihi nilai discount rate maka sudah pasti dapat dikatakan bahwa proyek layak untuk dikerjakan namun jika lebih kecil dari discount rate sekalipun nilai BCR-nya $>1$, kelayakan proyek masih perlu ditinjau ulang.

$\mathrm{IRR}=\mathrm{IR} 1-\mathrm{NPV} 1 \frac{\mathrm{IR} 2-\mathrm{IR} 1}{\mathrm{NPV} 2-\mathrm{NPV} 1}$

Dimana :

IRR = Internal Rate Of Return

IR1 = Tingkat bunga untuk penetapan ke-1

IR2 = Tingkat bunga untuk penetapan ke-2

NPV1 = NPV dari hasil IR1

NPV2 $=$ NPV dari hasil IR2

\section{Analisis Sensitivitas}

Nilai-nilai parameter dalam studi kelayakan proyek biasanya diestimasikan besarnya maka jelas nilai-nilai tersebut tidak dapat lepas dari kesalahan. Maksudnya dapat saja nilai tersebut lebih besar ataupun lebih kecil dari hasil estimasi yang diperoleh atau berubah pada saat-saat tertentu.

\section{METODELOGI PENELITIAN \\ Tahapan Penelitian}

Tahapan dalam penelitian diawali dengan studi untuk mengidentifikasi wilayah suatu lokasi, mengenali wilayah serta permasalahannya sehingga dapat ditetapkan sebagai lokasi studi, mengidentifikasi datadata yang akan diperlukan, mengidentifikasi pustaka dan acuan yang akan digunakan serta mengidentifikasi perangkat lunak yang dapat diacu dalam proses analisis data. Dengan menetapkan tujuan yang menjadi sasaran studi dan identifikasi pustaka, dicoba untuk mendesain formulir survei berupa survei pendahuluan untuk menentukan desain sampel yang sangat dibutuhkan sebelum dilakukan survei secara menyeluruh serta menentukan data-data apa saja yang dibutuhkan. Berdasarkan survei menyeluruh tersebut akan diperoleh data lapangan sebagai data primer dan data sekunder diperoleh dari instansi yang terkait, literatur, jurnal ilmiah, studi terdahulu yang selanjutnya akan diolah dalam rangka penyusunan laporan.

\section{Lokasi dan Waktu Penelitian}

Lokasi yang dipilih dalam penelitian ini adalah rencana underpass pada simpang $\mathrm{Jl}$. Gatot Subroto-Jl. Ahmad Yani di Kota Denpasar. Adapun alasan yang menjadi pertimbangan dalam pemilihan lokasi penelitian adalah pentingnya dibangun jalan alternatif sebagai usaha untuk mengatasi permasalahan transportasi yang ada pada ruas Jl.Pidada - Jl.Gatot Subroto - Jl.Cokroaminoto - Jl.Mulawarman - Jl. Mataram.

\section{Sumber Data}

Data yang dibutuhkan dalam penelitian ini meliputi data primer dan data sekunder yang akan diperoleh secara langsung di lapangan, penelitian sebelumnya serta sumber-sumber informasi lainnya.

1. Data Primer

Data primer dalam penelitian ini melitputi data geometrik jalan, data kecepatan perjalanan, dan data komponen BOK.

2. Data Sekunder

Data sekunder dalam penelitian ini yaitu :

a. Data volume lalu lintas

b. Data asal tujuan perjalanan

c. Data statistik sosial ekonomi

d. Data biaya pembangunan underpass

\section{Variabel Penelitian}

Variabel-variabel dalam penelitian ini adalah sebagai berikut :

1. Arus dan komposisi lalu lintas

2. Kapasitas ruas jalan

3. Derajat kejenuhan ruas jalan

4. Kecepatan dan waktu tempuh

5. Biaya operasional kendaraan

6. Nilai waktu

7. Net present value

8. Benefit cost ratio

9. Internal rate of return 


\section{Analisis sensitivitas}

\section{Analisis Data} meliputi :

Analisis data yang akan dilakukan

1. Analisis manfaat pembangunan underpass

2. Analisis biaya pembangunan dan pemeliharaan underpass

3. Analisis kelayakan ekonomi pembangunan underpass.

\section{Analisis Sensitivitas}

Selanjutnya juga dilakukan analisis sensitivitas dengan mengubah nilai suatu variabel dan mengamati pengaruhnya terhadap kelayakan investasi.. Analisis sensitivitas dalam penelitian ini mengasumsikan keadaankeadaan seperti :

1. Biaya naik $20 \%$, manfaat tetap.

2. Biaya tetap, manfaat turun $20 \%$.

3. Biaya naik $20 \%$, manfaat turun $20 \%$.

\section{HASIL DAN PEMBAHASAN} Analisis Nilai Waktu Perjalanan

Dalam studi ini nilai waktu penumpang rata-rata dihitung 50\% dari pendapatannya. Jadi berdasarkan PDRB per kapita per jam kerja tahun 2014 sebesar Rp
3.798,79 didapat nilai waktu penumpang menjadi:

$$
\begin{aligned}
& =50 \% \times \operatorname{Rp} 3.798,79 \\
& =\quad \operatorname{Rp} 1.899,40 \text { per jam. }
\end{aligned}
$$

Dengan demikian nilai waktu penumpang per jam berdasarkan jenis kendaraan pada tahun 2014 adalah sebagai berikut:

- Sepeda Motor

$$
\begin{aligned}
& =\text { Rp. } 1.899,40 \times 1,35 \\
& =\text { Rp. 2.564,19 }
\end{aligned}
$$

- Kendaraan Ringan (Sedan, Utiliti)

$=$ Rp. $1.899,40 \times 2,70$

$=$ Rp. 5.128,37

- Bus (Bus Kecil, Besar)

$=$ Rp. $1.899,40 \times 17,40$

$=$ Rp. 33.049,50

- Truk (Truk Ringan, Sedang, Besar)

$=$ Rp. $1.899,40 \times 1,98$

$=$ Rp. 3.760,81

Tabel 1 adalah prediksi nilai waktu penumpang menurut jenis kendaraan hingga tahun 2035, dengan laju pertumbuhan PDRB sebesar 6,05\% per tahun. Pada tahun 2014, nilai waktu penumpang berdasarkan jenis kendaraan memiliki nilai yang bervariasi, dari Rp. 2.564,19/jam sampai dengan Rp.

\begin{tabular}{|c|c|c|c|c|}
\hline \multirow[b]{2}{*}{ Tahum } & \multirow[b]{2}{*}{$\begin{array}{l}\text { Sepeda Motor } \\
\text { (Rp/jam) }\end{array}$} & \multicolumn{2}{|c|}{ Nilai Waktu Per Jam } & \multirow[b]{2}{*}{$\begin{array}{c}\text { Truk } \\
\text { (Rp/jam) }\end{array}$} \\
\hline & & $\begin{array}{c}\text { Kendaraan Ringan } \\
\text { (Rp/jam) }\end{array}$ & $\begin{array}{c}\text { Bus } \\
\text { (Rp/jam) }\end{array}$ & \\
\hline 2014 & $2.564,19$ & $\begin{array}{ll}5.128,37 \\
\end{array}$ & $33.049,50$ & $3.760,81$ \\
\hline 2015 & $2.719,32$ & $5.438,64$ & $35.048,99$ & $3.988,33$ \\
\hline 2016 & $2.883,84$ & $5.767,67$ & $37.169,46$ & $4.229,63$ \\
\hline 2017 & $3.058,31$ & $6.116,62$ & $39.418,21$ & $4.485,52$ \\
\hline 2018 & $3.243,34$ & $6.486,67$ & $41.803,01$ & $4.756,89$ \\
\hline 2019 & $3.439,56$ & $6.879,12$ & $44.332,09$ & $5.044,69$ \\
\hline 2020 & $3.647,65$ & $7.295,30$ & $47.014,19$ & $5.349,89$ \\
\hline 2021 & $3.868,34$ & $7.736,67$ & $49.858,54$ & $5.673,56$ \\
\hline 2022 & $4.102,37$ & $8.204,74$ & $52.874,99$ & $6.016,81$ \\
\hline 2023 & $4.350,56$ & $8.701,13$ & $56.073,92$ & $6.380,83$ \\
\hline 2024 & $4.613,77$ & $9.227,54$ & $59.466,40$ & $6.766,87$ \\
\hline 2025 & $4.892,91$ & $9.785,81$ & $63.064,11$ & $7.176,26$ \\
\hline 2026 & $5.188,93$ & $10.377,85$ & $66.879,49$ & $7.610,42$ \\
\hline 2027 & $5.502,86$ & $11.005,71$ & $70.925,70$ & $8.070,86$ \\
\hline 2028 & $5.835,78$ & $11.671,56$ & $75.216,71$ & $8.559,14$ \\
\hline 2029 & $6.188,84$ & $12.377,69$ & $79.767,32$ & $9.076,97$ \\
\hline 2030 & $6.563,27$ & $13.126,54$ & $84.593,24$ & $9.626,13$ \\
\hline 2031 & $6.960,35$ & $13.920,69$ & $89.711,13$ & $10.208,51$ \\
\hline 2032 & $7.381,45$ & $14.762,89$ & $95.138,65$ & $10.826,12$ \\
\hline 2033 & $7.828,02$ & $15.656,05$ & $100.894,54$ & $11.481,10$ \\
\hline 2034 & $8.301,62$ & $16.603,24$ & $106.998,66$ & $12.175,71$ \\
\hline 2035 & $8.803,87$ & $17.607,74$ & $113.472,08$ & $12.912,34$ \\
\hline
\end{tabular}
33.049,50/jam.

Tabel 1

Nilai Waktu Penumpang Menurut Jenis Kendaraan

Sumber : Hasil Analisis, 2014

\section{Analisis BOK setelah Underpass}

Tabel 2 menampilkan hasil analisis BOK Sp. Jl. Gatot Subroto-Jl. Ahmad Yani ke Sp. Jl. Cokroaminoto-Jl. Maruti setelah pembangunan Underpass dari tahun 20162035. BOK pada tahun 2016 untuk beberapa jenis kendaraan yang melintasi Sp. Jalan Gatot
Subroto-Jalan Ahmad Yani ke Sp. Jl. Cokroaminoto-Jl. Maruti memiliki nilai yang bervariasi, dari Rp. 50,33/km (sepeda motor) sampai dengan Rp. 20.157,37/km (truk besar). Dengan besar inflasi Kota Denpasar, yaitu 6,11\% maka pada tahun 2035 BOK terbesar terjadi pada kendaraan jenis truk besar. 
Tabel 2

Analisis BOK Sp. Jalan Gatot Subroto-Jalan Ahmad Yani ke Sp. Jalan Cokroaminoto-Jalan Maruti setelah Underpass

\begin{tabular}{|c|c|c|c|c|c|c|c|c|}
\hline \multirow{2}{*}{ Tahun } & \multicolumn{8}{|c|}{ BOK per Km (Rp) } \\
\hline & Sedan & Utiliti & Bus Kecil & Bus Besar & Truk Ringan & Truk Sedang & Truk Besar & Sepeda Motor \\
\hline 2016 & $5.116,82$ & $4.908,64$ & $7.070,17$ & $18.501,91$ & $6.744,12$ & $13.769,50$ & $20.157,37$ & 50,33 \\
\hline 2017 & $5.429,45$ & $5.208,56$ & $7.502,15$ & $19.632,38$ & $7.156,19$ & $14.610,82$ & $21.388,99$ & 53,41 \\
\hline 2018 & $5.761,19$ & $5.526,81$ & $7.960,53$ & $20.831,92$ & $7.593,43$ & $15.503,54$ & $22.695,86$ & 56,67 \\
\hline 2019 & $6.113,20$ & $5.864,49$ & $8.446,92$ & $22.104,75$ & $8.057,39$ & $16.450,81$ & $24.082,57$ & 60,13 \\
\hline 2020 & $6.486,72$ & $6.222,81$ & $8.963,03$ & $23.455,35$ & $8.549,70$ & $17.455,95$ & $25.554,02$ & 63,81 \\
\hline 2021 & $6.883,06$ & $6.603,03$ & $9.510,67$ & $24.888,47$ & $9.072,08$ & $18.522,51$ & $27.115,37$ & 67,71 \\
\hline 2022 & 7.303,61 & $7.006,47$ & $10.091,77$ & $26.409,15$ & $9.626,39$ & $19.654,23$ & $28.772,12$ & 71,84 \\
\hline 2023 & $7.749,86$ & $7.434,57$ & $10.708,38$ & $28.022,75$ & $10.214,56$ & $20.855,11$ & $30.530,09$ & 76,23 \\
\hline 2024 & $8.223,38$ & $7.888,82$ & $11.362,66$ & $29.734,94$ & $10.838,67$ & $22.129,36$ & $32.395,48$ & 80,89 \\
\hline 2025 & $8.725,83$ & $8.370,83$ & $12.056,92$ & $31.551,75$ & $11.500,91$ & $23.481,46$ & $34.374,85$ & 85,83 \\
\hline 2026 & $9.258,97$ & $8.882,29$ & $12.793,60$ & $33.479,56$ & $12.203,62$ & $24.916,18$ & $36.475,15$ & 91,08 \\
\hline 2027 & $9.824,70$ & $9.424,99$ & $13.575,29$ & $35.525,16$ & $12.949,26$ & $26.438,55$ & $38.703,78$ & 96,64 \\
\hline 2028 & $10.424,99$ & $10.000,86$ & $14.404,74$ & $37.695,75$ & $13.740,46$ & $28.053,95$ & $41.068,58$ & 102,55 \\
\hline 2029 & $11.061,95$ & $10.611,91$ & $15.284,87$ & $39.998,96$ & $14.580,00$ & $29.768,05$ & $43.577,87$ & 108,81 \\
\hline 2030 & $11.737,84$ & $11.260,30$ & $16.218,77$ & $42.442,90$ & $15.470,84$ & $31.586,87$ & $46.240,48$ & 115,46 \\
\hline 2031 & $12.455,02$ & $11.948,31$ & $17.209,74$ & $45.036,16$ & $16.416,11$ & $33.516,83$ & $49.065,77$ & 122,52 \\
\hline 2032 & $13.216,02$ & $12.678,35$ & $18.261,25$ & $47.787,87$ & $17.419,13$ & $35.564,71$ & $52.063,69$ & 130,00 \\
\hline 2033 & $14.023,52$ & $13.452,99$ & $19.377,02$ & $50.707,70$ & $18.483,44$ & $37.737,72$ & $55.244,78$ & 137,94 \\
\hline 2034 & $14.880,36$ & $14.274,97$ & $20.560,95$ & $53.805,94$ & $19.612,78$ & $40.043,49$ & $58.620,24$ & 146,37 \\
\hline 2035 & $15.789,55$ & $15.147,17$ & $21.817,23$ & $57.093,49$ & $20.811,12$ & $42.490,15$ & $62.201,94$ & 155,32 \\
\hline
\end{tabular}

Sumber : Hasil Analisis, 2014

\section{Penghematan Biaya Pemakai Jalan}

Nilai komponen PBPJ dapat dilihat pada Tabel 3 dan hasil analisis PBPJ dapat dilihat pada Tabel 4. Perbedaan BOK sebelum dan setelah pembangunan underpass untuk sepeda motor, yaitu Rp. 72,22/ km dan Rp. 50,33/ km. Hal ini juga dialami dengan semua jenis kendaraan lainnya.

Tabel 3

Harga Komponen-Komponen PBPJ

\begin{tabular}{|c|c|c|c|c|c|c|c|c|c|c|c|}
\hline No. & Komponen PBPJ & Notasi & Satuan & Sedan & Utiliti & Bus Kecil & Bus Besar & Truk Ringan & Truk Sedang & Truk Besar & Sepeda Notor \\
\hline 1 & BOK jalan Eksisting & $\mathrm{BOK}_{\mathrm{eks}}$ & $\mathrm{Rp} / \mathrm{km}$ & $10.947,68$ & $10.090,20$ & $13.367,57$ & $39.560,89$ & $12.087,56$ & $24.071,30$ & $40.317,24$ & 72,22 \\
\hline 2 & BOK setelah Underpass & $\mathrm{BOK}_{\text {und }}$ & $\mathrm{Rp} / \mathrm{km}$ & $5.116,82$ & $4.908,64$ & $7.070,17$ & $18.501,91$ & $6.744,12$ & $13.769,50$ & $20.157,37$ & 50,33 \\
\hline 3 & Panjang jalan Eksisting & $\mathrm{D}_{\mathrm{eks}}$ & $\mathrm{Km}$ & 1,10 & 1,10 & 1,10 & 1,10 & 1,10 & 1,10 & 1,10 & 1,10 \\
\hline 4 & Panjang jalan setelah Underpass & $\mathrm{D}_{\text {und }}$ & $\mathrm{Km}$ & 1,10 & 1,10 & 1,10 & 1,10 & 1,10 & 1,10 & 1,10 & 1,10 \\
\hline 5 & Kecepatan di jalan Eksisting & $V_{\text {eks }}$ & $\mathrm{Km} / \mathrm{jam}$ & 15,17 & 15,17 & 15,17 & 15,17 & 15,17 & 15,17 & 15,17 & 15,17 \\
\hline 6 & Kecepatan setelah Underpass & $\mathrm{V}_{\text {und }}$ & $\mathrm{Km} / \mathrm{jam}$ & 42,85 & 42,85 & 42,85 & 42,85 & 42,85 & 42,85 & 42,85 & 42,85 \\
\hline 7 & Nilai waktu kendaraan & $\mathrm{T}_{\mathrm{v}}$ & Rp/jam & $5.767,67$ & $5.767,67$ & $37.169,46$ & $37.169,46$ & $4.229,63$ & $4.229,63$ & $4.229,63$ & $2.883,84$ \\
\hline
\end{tabular}

Sumber : Hasil Analisis, 2014

Tabel 4

PBPJ Sp. Jalan Gatot Subroto-Ahmad Yani ke Sp. Cokroaminoto-Maruti

\begin{tabular}{|c|c|c|c|c|c|c|c|c|}
\hline \multirow{2}{*}{ Tahun } & \multicolumn{8}{|c|}{ Penghematan Biaya Pemakai Jalan (Rp/km) } \\
\hline & Sedan & Utiliti & Bus Kecil & Bus Besar & Truk Ringan & Truk Sedang & Truk Berat & Sepeda Motor \\
\hline 2016 & 6.684 & 5.970 & 8.668 & 24.906 & 6.076 & 11.530 & 22.374 & 159 \\
\hline 2017 & 7.089 & 6.331 & 9.193 & 26.413 & 6.444 & 12.228 & 23.728 & 169 \\
\hline 2018 & 7.517 & 6.714 & 9.749 & 28.011 & 6.833 & 12.967 & 25.163 & 179 \\
\hline 2019 & 7.972 & 7.120 & 10.339 & 29.706 & 7.247 & 13.752 & 26.686 & 190 \\
\hline 2020 & 8.455 & 7.551 & 10.964 & 31.503 & 7.685 & 14.584 & 28.300 & 201 \\
\hline 2021 & 8.966 & 8.008 & 11.628 & 33.409 & 8.150 & 15.466 & 30.012 & 214 \\
\hline 2022 & 9.508 & 8.492 & 12.331 & 35.430 & 8.643 & 16.402 & 31.828 & 226 \\
\hline 2023 & 10.084 & 9.006 & 13.077 & 37.574 & 9.166 & 17.394 & 33.753 & 240 \\
\hline 2024 & 10.694 & 9.551 & 13.868 & 39.847 & 9.721 & 18.447 & 35.796 & 255 \\
\hline 2025 & 11.341 & 10.129 & 14.707 & 42.257 & 10.309 & 19.563 & 37.961 & 270 \\
\hline 2026 & 12.027 & 10.742 & 15.597 & 44.814 & 10.933 & 20.746 & 40.258 & 286 \\
\hline 2027 & 12.755 & 11.392 & 16.541 & 47.525 & 11.594 & 22.001 & 42.693 & 304 \\
\hline 2028 & 13.526 & 12.081 & 17.542 & 50.401 & 12.295 & 23.333 & 45.276 & 322 \\
\hline 2029 & 14.344 & 12.812 & 18.603 & 53.450 & 13.039 & 24.744 & 48.016 & 342 \\
\hline 2030 & 15.212 & 13.587 & 19.728 & 56.684 & 13.828 & 26.241 & 50.921 & 362 \\
\hline 2031 & 16.133 & 14.409 & 20.922 & 60.113 & 14.665 & 27.829 & 54.001 & 384 \\
\hline 2032 & 17.109 & 15.281 & 22.188 & 63.750 & 15.552 & 29.512 & 57.268 & 407 \\
\hline 2033 & 18.144 & 16.205 & 23.530 & 67.607 & 16.493 & 31.298 & 60.733 & 432 \\
\hline 2034 & 19.241 & 17.185 & 24.954 & 71.697 & 17.491 & 33.191 & 64.407 & 458 \\
\hline 2035 & 20.406 & 18.225 & 26.463 & 76.034 & 18.549 & 35.200 & 68.304 & 486 \\
\hline
\end{tabular}

Sumber : Hasil Analisis, 2014 
Berdasarkan Tabel 4, PBPJ Sp. Jl Gatot Subroto-Jl. Ahmad Yani ke Sp. Jl. Cokroaminoto-Jl. Maruti setelah pembangunan underpass, terjadi pada semua jenis kendaraan. Pada tahun 2016, penghematan terbesar terjadi pada kendaraan jenis bus besar.

Berdasarkan Tabel 5 dan 6, pada tahun 2016 jumlah sepeda motor yang melintasi Sp. Jl. Gatot Subroto-Jl. Ahmad Yani ke Sp. Jl. Cokroaminoto-Jl. Maruti adalah 8.101.103 kendaraan. Dengan jumlah PBPJ Rp. 159,00/ km maka diperoleh total PBPJ untuk sepeda motor sebesar Rp. 1.289.527.978,00/tahun. Jadi total PBPJ pada tahun 2016 untuk semua jenis kendaraan yang melintas pada Sp. Jl. Gatot Subroto-Jl. Ahmad Yani ke Sp. Jl. Cokroaminoto-Jl. Maruti adalah sebesar Rp. 9.330.159.847,00.

Tabel 5

Jumlah Kendaraan yang Melewati Sp. Jl. Gatot Subroto-Jl. Ahmad Yani ke Sp. Jl. Cokroaminoto-Jl. Maruti selama Setahun

\begin{tabular}{|c|c|c|c|c|c|c|c|c|}
\hline \multirow{2}{*}{ Tahun } & \multicolumn{7}{|c|}{ Jumlah Kendaraan (Kend/tahun) } & \multirow[b]{2}{*}{ Sepeda Motor } \\
\hline & Sedan & Utiliti & Bus Kecil & Bus Besar & Truk Ringan & Truk Sedang & Truk Berat & \\
\hline 2016 & 1.060 .285 & 117.809 & 3.275 & 2.183 & 3.821 & 5.094 & 3.821 & 8.101 .103 \\
\hline 2017 & 1.124 .432 & 124.937 & 3.473 & 2.315 & 4.052 & 5.403 & 4.052 & 8.591 .219 \\
\hline 2018 & 1.192 .460 & 132.496 & 3.683 & 2.456 & 4.297 & 5.730 & 4.297 & 9.110 .988 \\
\hline 2019 & 1.264 .604 & 140.512 & 3.906 & 2.604 & 4.557 & 6.076 & 4.557 & 9.662 .203 \\
\hline 2020 & 1.341.112 & 149.012 & 4.142 & 2.762 & 4.833 & 6.444 & 4.833 & 10.246 .766 \\
\hline 2021 & 1.422 .250 & 158.028 & 4.393 & 2.929 & 5.125 & 6.834 & 5.125 & 10.866 .696 \\
\hline 2022 & 1.508 .296 & 167.588 & 4.659 & 3.106 & 5.435 & 7.247 & 5.435 & 11.524.131 \\
\hline 2023 & 1.599 .548 & 177.728 & 4.941 & 3.294 & 5.764 & 7.686 & 5.764 & 12.221.341 \\
\hline 2024 & 1.696 .320 & 188.480 & 5.240 & 3.493 & 6.113 & 8.150 & 6.113 & 12.960 .732 \\
\hline 2025 & 1.798 .948 & 199.883 & 5.557 & 3.704 & 6.483 & 8.644 & 6.483 & 13.744 .856 \\
\hline 2026 & 1.907 .784 & 211.976 & 5.893 & 3.929 & 6.875 & 9.167 & 6.875 & 14.576 .420 \\
\hline 2027 & 2.023 .205 & 224.801 & 6.249 & 4.166 & 7.291 & 9.721 & 7.291 & 15.458 .293 \\
\hline 2028 & 2.145 .609 & 238.401 & 6.627 & 4.418 & 7.732 & 10.309 & 7.732 & 16.393 .520 \\
\hline 2029 & 2.275 .418 & 252.824 & 7.028 & 4.686 & 8.200 & 10.933 & 8.200 & 17.385 .328 \\
\hline 2030 & 2.413.081 & 268.120 & 7.454 & 4.969 & 8.696 & 11.594 & 8.696 & 18.437 .140 \\
\hline 2031 & 2.559 .072 & 284.341 & 7.904 & 5.270 & 9.222 & 12.296 & 9.222 & 19.552 .587 \\
\hline 2032 & 2.713 .896 & 301.544 & 8.383 & 5.588 & 9.780 & 13.040 & 9.780 & 20.735 .519 \\
\hline 2033 & 2.878 .087 & 319.787 & 8.890 & 5.927 & 10.371 & 13.829 & 10.371 & 21.990 .018 \\
\hline 2034 & 3.052 .211 & 339.135 & 9.428 & 6.285 & 10.999 & 14.665 & 10.999 & 23.320.414 \\
\hline 2035 & 3.236 .870 & 359.652 & 9.998 & 6.665 & 11.664 & 15.553 & 11.664 & 24.731.299 \\
\hline
\end{tabular}

Sumber : Hasil Analisis, 2014

Tabel 6

PBPJ Sp. Jl. Gatot Subroto-Jl. Ahmad Yani ke Sp. Jl. Cokroaminoto-Jl. Maruti selama Setahun

\begin{tabular}{|c|c|c|c|c|c|c|c|c|c|}
\hline \multirow{2}{*}{ Tahun } & \multicolumn{8}{|c|}{ Penghematan Biaya Pemakai Jalan (Rp/tahun) } & \multirow{2}{*}{ Jumlah } \\
\hline & Sedan & Utiliti & Bus Kecil & Bus Besar & Truk Ringan & Truk Sedang & Truk Berat & Sepeda Motor & \\
\hline 2016 & 7.087.109.406 & 703.311 .835 & 28.389 .293 & 54.378 .699 & 23.215 .199 & 58.739 .807 & 85.487 .631 & 1.289 .527 .978 & 9.330 .159 .847 \\
\hline 2017 & 7.515.879.525 & 745.862 .201 & 30.106 .846 & 57.668 .610 & 24.619 .718 & 62.293 .565 & 90.659 .632 & 1.367.544.421 & 9.894 .634 .518 \\
\hline 2018 & 7.970 .590 .236 & 790.986 .864 & 31.928 .310 & 61.157 .561 & 26.109.211 & 66.062 .326 & 96.144 .540 & 1.450.280.858 & 10.493.259.906 \\
\hline 2019 & 8.452 .810 .945 & 838.841 .569 & 33.859 .972 & 64.857 .593 & 27.688 .818 & 70.059 .097 & 101.961.285 & 1.538 .022 .850 & 11.128.102.130 \\
\hline 2020 & 8.964 .206 .008 & 889.591 .484 & 35.908 .501 & 68.781 .478 & 29.363 .992 & 74.297.672 & 108.129.942 & 1.631.073.232 & 11.801.352.309 \\
\hline 2021 & 9.506 .540 .471 & 943.411 .769 & 38.080 .965 & 72.942 .757 & 31.140 .513 & 78.792 .681 & 114.671 .804 & 1.729 .753 .163 & 12.515 .334 .124 \\
\hline 2022 & 10.081 .686 .170 & 1.000.488.181 & 40.384 .863 & 77.355 .794 & 33.024 .514 & 83.559 .639 & 121.609 .448 & 1.834.403.229 & 13.272 .511 .838 \\
\hline 2023 & 10.691.628.183 & 1.061.017.716 & 42.828 .148 & 82.035 .819 & 35.022 .497 & 88.614 .997 & 128.966 .820 & 1.945 .384 .625 & 14.075 .498 .805 \\
\hline 2024 & 11.338 .471 .688 & 1.125 .209 .288 & 45.419 .251 & 86.998 .987 & 37.141 .359 & 93.976.204 & 136.769 .312 & 2.063.080.394 & 14.927.066.482 \\
\hline 2025 & 12.024 .449 .225 & 1.193 .284 .450 & 48.167.115 & 92.262 .425 & 39.388.411 & 99.661 .764 & 145.043 .855 & 2.187.896.758 & 15.830 .154 .004 \\
\hline 2026 & 12.751 .928 .403 & 1.265 .478 .159 & 51.081 .226 & 97.844 .302 & 41.771 .410 & 105.691.301 & 153.819 .009 & 2.320.264.512 & 16.787 .878 .322 \\
\hline 2027 & 13.523 .420 .072 & 1.342 .039 .588 & 54.171 .640 & 103.763 .882 & 44.298 .580 & 112.085 .625 & 163.125 .059 & 2.460 .640 .515 & 17.803.544.960 \\
\hline 2028 & 14.341.586.986 & 1.423.232.983 & 57.449 .024 & 110.041 .597 & 46.978 .644 & 118.866 .805 & 172.994 .125 & 2.609.509.266 & 18.880 .659 .430 \\
\hline 2029 & 15.209.252.999 & 1.509 .338 .578 & 60.924 .690 & 116.699 .114 & 49.820 .852 & 126.058 .247 & 183.460 .269 & 2.767.384.577 & 20.022.939.326 \\
\hline 2030 & 16.129 .412 .805 & 1.600 .653 .562 & 64.610 .634 & 123.759 .410 & 52.835 .013 & 133.684 .771 & 194.559 .616 & 2.934.811.344 & 21.234.327.155 \\
\hline 2031 & 17.105 .242 .280 & 1.697 .493 .103 & 68.519 .577 & 131.246 .854 & 56.031 .532 & 141.772 .699 & 206.330 .472 & 3.112.367.430 & 22.519.003.948 \\
\hline 2032 & 18.140.109.438 & 1.800.191.436 & 72.665 .012 & 139.187.289 & 59.421 .439 & 150.349 .948 & 218.813.466 & 3.300 .665 .659 & 23.881.403.687 \\
\hline 2033 & 19.237 .586 .059 & 1.909.103.017 & 77.061 .245 & 147.608 .120 & 63.016.437 & 159.446 .120 & 232.051 .681 & 3.500.355.932 & 25.326.228.610 \\
\hline 2034 & 20.401 .460 .015 & 2.024.603.750 & 81.723 .450 & 156.538 .411 & 66.828 .931 & 169.092 .610 & 246.090 .807 & 3.712.127.466 & 26.858 .465 .441 \\
\hline 2035 & 21.635 .748 .346 & 2.147.092.277 & 86.667 .719 & 166.008 .985 & 70.872 .081 & 179.322 .713 & 260.979 .301 & 3.936.711.177 & 28.483 .402 .600 \\
\hline
\end{tabular}

Sumber : Hasil Analisis, 2014 


\section{ANALISIS EKONOMI}

Kelayakan pembangunan underpass ini ditentukan menurut nilai NPV, BCR dan IRR. Dalam penelitian ini analisis dilakukan dengan asumsi tiga tingkat suku bunga, yaitu: $12 \%, 15 \%$ dan $18 \%$ per tahun.

\section{Komponen Biaya}

Biaya pembangunan underpass terdiri dari biaya pembebasan lahan, perkiraan biaya konstruksi jalan serta biaya pengelolaan. Besar biaya pembebasan lahan dan biaya konstruksi ditunjukkan pada Tabel.7.

Tabel 7

Biaya Pembebasan Lahan dan Biaya Konstruksi

\begin{tabular}{llr}
\hline No. & \multicolumn{1}{c}{ Uraian Pekerjaan } & Biaya (Rp.) \\
\hline \hline A & Biaya Pembebasan Lahan & 15.050 .994 .400 \\
B & Biaya Konstruksi Jalan & \\
1 & Umum & 18.123 .351 .288 \\
2 & Drainase & 42.651 .907 .382 \\
3 & Pekerjaan Tanah & 8.634 .890 .922 \\
4 & Pelebaran Pekerasan Jalan & 3.390 .970 .820 \\
5 & Pekerasan Berbutir & 7.189 .201 .604 \\
6 & Pekerasan Aspal & 11.507 .740 .421 \\
7 & Struktur & 66.418 .737 .018 \\
8 & Pengembalian Kondisi dan Pekerjaan Minor & 14.532 .610 .727 \\
9 & Pekerjaan Harian & 508.873 .849 \\
10 & Pekerjaan Pemeliharaan Rutin & 556.268 .804 \\
Total Biaya Investasi & 188.565 .547 .235 \\
PPN 1O\% & 18.856 .554 .724 \\
Total Biaya Investasi + PPN 10\% & 207.422 .101 .959 \\
\hline
\end{tabular}

Sumber : Hasil Analisis, 2014

\section{KOMPONEN MANFAAT}

Manfaat yang diperoleh dari adanya pembangunan underpass yang dihitung hanyalah komponen penghematan BOK dan nilai waktu. Besar komponen manfaat yang diperoleh dapat dilihat pada Tabel 6 .

\section{Hasil Analisis Kelayakan Ekonomi}

Dari analisis kelayakan ekonomi yang dilakukan menurut tiga kriteria analisis (NPV, BCR, danIRR) terhadap tiga tingkat suku bunga (12\%, 15\%, dan 18\% per tahun) didapatkan hasil seperti pada Tabel 8 .

Tabel 8

Hasil Analisis Kelayakan Ekonomi

\begin{tabular}{llccc}
\hline No. & Uraian & NPV (Rp.) & BCR & IRR (\%) \\
\hline 1 & Skenario I & $347.440 .337 .699,00$ & 2,305 & \\
2 & Skenario II & $233.462 .340 .102,00$ & 1,948 & 30,81 \\
3 & Skenario III & $152.907 .089 .867,00$ & 1,664 & \\
\hline
\end{tabular}

Sumber : Hasil Analisis, 2014

\section{Hasil Analisis Sensitivitas}

Dari hasil analisis sensitivitas yang dilakukan dengan masing-masing kondisi terburuk maka diperoleh nilai NPV, BCR dan IRR seperti yang ditunjukkan pada Tabel 9.
Berdasarkan Tabel 9, terdapat variasi nilai NPV, BCR dan IRR untuk kondisi I (biaya naik 20\%, manfaat tetap), kondisi II (biaya tetap, manfaat turun 20\%) dan kondisi III (biaya naik 20\%, manfaat turun 20\%).

Tabel 9

Hasil Analisis Sensitivitas

\begin{tabular}{lcccc}
\hline Kondisi & Uraian & NPV (Rp.) & BCR & IRR (\%) \\
\hline \multirow{3}{*}{1} & DR $12 \%$ & $294.192 .656 .848,00$ & 1,921 & - \\
& DR $15 \%$ & $184.221 .741 .756,00$ & 1,624 & \\
2 & DR $18 \%$ & $106.847 .922 .937,00$ & 1,387 & \\
& DR $12 \%$ & $224.704 .589 .308,00$ & 1,844 & 24,61 \\
& DR $15 \%$ & $137.529 .273 .735,00$ & 1,559 & - \\
3 & DR $18 \%$ & $76.266 .504 .424,00$ & 1,331 & \\
& DR $12 \%$ & $171.456 .908 .457,00$ & 1,537 & \\
\hline
\end{tabular}

Sumber : Hasil Analisis, 2014 


\section{SIMPULAN DAN SARAN \\ Simpulan}

Berdasarkan analisis dan pembahasan maka diperoleh simpulan sebagai berikut :

1. Besar biaya yang diperlukan untuk mewujudkan underpass (harga tahun 2014) adalah sebesar Rp. 207.422.101.959,00.

2. Manfaat langsung dari pembangunan underpass adalah berupa penghematan BOK dan nilai waktu. Dimana jumlah total PBPJ setahun sebesar Rp. 61.547.498.194,00.

3. Secara umum proyek pembangunan underpass layak secara ekonomi. Dimana dari hasil analisis yang dilakukan dengan asumsi tiga tingkat suku bunga bank yaitu: $12 \%, 15 \%$ dan $18 \%$ per tahun didapatkan nilai NPV positif, BCR lebih dari satu dan IRR diatas tingkat suku bunga bank.

Berdasarkan analisis sensitivitas yang dilakukan dengan tiga asumsi tingkat suku bunga bank pada masing-masing kondisi yang ada (kondisi I dengan menaikkan biaya 20\% dan manfaat tetap, kondisi II dengan menaikkan biaya $20 \%$ dan manfaat tetap, dan kondisi III dengan menaikkan biaya $20 \%$ dan menurunkan manfaat 20\%) diperoleh hasil bahwa proyek sensitif untuk kondisi I dan III. Namun proyek tidak sensitif untuk asumsi pada kondisi II.

\section{Saran}

Beberapa saran yang dapat diusulkan dari penelitian ini yaitu :

1. Dalam menganalisis pertumbuhan lalu-lintas yang melewati ruasjalan di sekitar wilayah underpass perlu mempertimbangkan pengaruh perubahan tata guna lahan yang dapat terjadi di sekitar underpass.

2. Dalam studi selanjutnya disarankan agar memperhitungkan kebutuhan penambahan lajur lalu lintas.

\section{DAFTAR PUSTAKA}

Ariyasa, P. A. 2013. Analisis Kinerja Simpang dan Pembebanan Ruas Jalan Pada Pengelolaan Lalu Lintas Dengan Sistem Satu Arah (Studi Kasus Simpang Jalan Gatot Subroto - Jalan Mulawarman - Jalan Ahmad Yani). (Tugas Akhir yang tidak dipublikasikan, Jurusan Teknik Sipil Fakultas Teknik Universitas Udayana, 2013)

Badan Pusat Statistik Kota Denpasar. 2013. Denpasar Dalam Angka 2012. Denpasar
Badan Pusat Statistik Provinsi Bali. 2013. Produk Dometik Regional Bruto Provinsi Bali 2008-2012. Bali

Balai Pelaksanaan Jalan Nasional VIII Denpasar. 2013. Rencana Underpass dan Pola Sirkulasi Lalu Lintas di Jalan Gatot Subroto Denpasar

Departemen Pekejaan Umum. 1997. Manual Kapasitas Jalan Indonesia (MKJI). Direktorat Jenderal Bina Marga, Jakarta

Departemen Pekejaan Umum Provinsi Bali. 2014. Studi Kelayakan Underpass Pada Simpang Jalan Gatot SubrotoCokroaminoto Denpasar

Google Maps. 2014. “Pulau Bali, Denpasar”. Available from: URL: https://maps.google.com/. Diakses 11 Januari 2014

Hensher, D, Milthrope F, Smith N and Barnanrd P. 1988. Urban Tolled Roads and The Value of Travel Time Savings. Institute of Transport Study Working Paper No. 47. University of Sydney. Australia

LPM-ITB. 1997. Modul Pelatihan, Studi Kelayakan Proyek Transportasi, Lembaga Pengabdian Masyarakat ITB bekerjasama dengan kelompok Bidang Keahlian Rekayasa Transportasi Jurusan Teknik Sipil ITB. Bandung

Mahendra, I. P. G. 2013. Analisis Kinerja Simpang Tak Bersinyal dan Ruas Jalan di Kota Denpasar (Studi Kasus Simpang Tak Bersinyal Jalan Gatot Subroto - Jalan Mulawarman - Jalan Mataram). (Tugas Akhir yang tidak dipublikasikan, Jurusan Teknik Sipil Fakultas Teknik Universitas Udayana, 2013)

Morlok, E. K. 1991. Pengantar Teknik dan Perencanaan Transportasi. Terjemahan Johan K.Hainim. Penerbit Erlangga. Jakarta

Moskowitz, K. 1956. California Method of Assigning Diverted Traffic to Proposed Freeways. Highway Reasearch Board, Bulletin No. 130. California 
Parmini, N. P. M. 2006. Pra Studi Kelayakan Jalan Tol (Studi Kasus Ruas Kuta Tanah Lot - Soka). Tugas Akhir yang tidak dipublikasikan, Jurusan Teknik Sipil Fakultas Teknik Universitas Udayana, 2006)

Peraturan Pemerintah Republik Indonesia, Nomor 32 Tahun 2011. Tentang Volume Lalu Lintas

Santosa, A. 2010. Studi Kelayakan (Feasibility Study). Penerbit PT. Elex Media Komputindo. Jakarta

Sandiguna, I. G. B. 2013. Analisis Kinerja dan Alternatif Pengaturan Simpang Bersinyal (Studi Kasus Simpang Gatot Subroto - HOS. Cokroaminoto). (Tugas Akhir yang tidak dipublikasikan, Jurusan Teknik Sipil
Fakultas Teknik Universitas Udayana, 2013)

Saodang, H. 2004. Buku I Geometrik jalan, Konstruksi Jalan Raya. Penerbit Nova. Bandung

Tamin dan Nahdalina. 1998. "Studi Penentuan Tarif Tol Rencana Ruas Jalan GempolPasuruan-Rojoso oleh Tunggal Suro Budho H” (Tugas Akhir, 2003). Malang

Tamin, O. Z. 2000. Perencanaan dan Pemodelan Transportasi. Penerbit ITB. Bandung

Transportations Research Board. 1994. Highway Capacity Manual Special Report 209. National Research Council. Washington DC 